\title{
The Changing Morphology of Indoor Ecosystems in the Twenty-first Century Driven by Technological, Climatic, and Sociodemographic Forces
}

\author{
Daniel Stokols \\ School of Social Ecology, University of California, Irvine, United States
}

\section{Abstract}

The majority of humans reside in urban regions and spend most of their time in indoor environments such as residential, educational, occupational, transportation, and health-care facilities. Interior settings affect occupants' health and behavior through their design, and chemical, microbial, and social features. The initial portion of this paper describes ecological psychologists' conceptions of indoor environments as self-contained and distinctly bounded ecobehavioral systems, with evidence for the behavioral and health effects of homes, workplaces, and other kinds of indoor ecosystems cited. The ensuing sections examine contemporary changes in the structure and functioning of indoor ecosystems propelled by the digitalization of society, global climate change, and sociodemographic shifts toward population aging, income inequality, and anti-immigrant views in many countries. Transdisciplinary action research is needed to understand and manage rapid changes in indoor ecosystems, as evidenced by the increasing permeability of their spatial and temporal boundaries, modifications of their structural features, and shifts in the distribution of certain categories of settings within host communities. Effective collaboration among academic and nonacademic partners spanning diverse fields and multiple environmental scales is likewise essential for developing broad-gauged solutions to enhance the healthfulness and sustainability of indoor ecosystems as they continue to evolve in future years.

Keywords: changing structure prevalence of indoor behavior settings, cybersphere, global climate change, sociodemographic trends, transdisciplinary action research

1 Corresponding author: dstokols@uci.edu. 


\section{Overview}

Macrosocietal conceptions of human and social ecology have given relatively little attention to the structure and functioning of indoor ecosystems. One branch of ecological science that has focused on people's transactions with their interior environments is ecological-environmental psychology. Indoor environments are proximal to individuals' everyday behavior and experiences, so it is unsurprising that ecologically oriented psychologists have examined several features of indoor ecosystems in their research. Psychologists Roger Barker (1968) and Urie Bronfenbrenner (1979) have played prominent roles in studying people's transactions with their immediate behavior settings, such as homes, workplaces, schools, and health-care environments. Yet, their conceptions of indoor ecosystems have focused more on the existing characteristics and conditions of settings themselves (e.g., the roles and resources available to current and prospective members of settings) than on their evolutionary structural changes over time.

The Anthropocene epoch of Earth history spanning the twentieth and twentyfirst centuries has spawned rapid and substantial changes in the structure and functioning of human environments (Steffen et al., 2015). This paper focuses on the changing morphology of indoor ecosystems during the early twenty-first century as a consequence of powerful technological, climatic, and sociodemographic forces. The proposed conceptualization of indoor ecosystem morphology and change draws on existing empirical evidence for these very forces, which are expected to result in accelerated changes in the structure and prevalence of certain categories of interior space. However, this paper does not present new primary data documenting the changes in those settings projected to occur in the coming decades. Rather, it offers a theoretical and programmatic analysis of important yet previously neglected questions for future study about the changing morphology of indoor ecosystems.

Developing a more complete understanding of how indoor human environments are being reshaped by macrolevel societal forces necessarily requires a multiscale, transdisciplinary analysis that brings together microlevel studies of people's relationships with their everyday local environments; it also considers the diverse array of community, societal, and global forces that are reconfiguring their immediate local surroundings (Stokols, 2018). Transdisciplinarity is a form of scholarly inquiry that integrates concepts and methods from diverse fields to create novel conceptual frameworks and multimethod approaches for understanding scientific and societal problems (cf. Rosenfield, 1992).

Future studies of the changing morphology of indoor ecosystems will require guidance, especially from translational forms of transdisciplinary research-notably, integrative research spanning multiple fields that seeks not only to better understand complex scientific and societal problems, but also to translate empirical findings from 
rigorous research into practical strategies (e.g., new environmental design, urban planning, and public policy innovations) to ameliorate and ultimately resolve those problems. Prior writings have referred to this translational form of transdisciplinary scholarship and practice as "transdisciplinary action research" (Stokols, 2006), strongly rooted in Kurt Lewin's (1951) dictum that "there is nothing so practical as a good theory" (p. 169). The proposed analysis of morphological change in indoor ecosystems is intended to serve not only as a framework for future transdisciplinary scholarship, but also a basis for devising evidence-based strategies to better manage environmental change and enhance rather than hinder human behavior, health, and the sustainability of our surroundings. As a case in point, the projected losses of buildings situated near shorelines caused by increasing sea level rise in the coming years call for new environmental planning and public policy solutions that consider anticipated migratory patterns and the needs of growing numbers of climate refugees. Those solutions to complex environmental and societal problems can only be developed through action-oriented collaborations among academic and nonacademic partners bridging multiple disciplines and fields.

What follows is a brief summary of the concepts and methods developed by ecological and environmental psychologists for understanding people's relationships with their everyday local environments. Subsequent sections identify key facets of indoor ecosystem morphology and the technological, environmental, and sociodemographic forces that are altering the structure and prevalence of various kinds of indoor settings. The concluding portion of this article considers promising directions for future transdisciplinary action research on current and projected changes in our indoor surroundings.

\section{Ecological Research on People's Interactions With Their Indoor Environments}

Studies of time use in several countries show that people spend the largest portion of their hours each day and over their lifetimes indoors (National Research Council Committee on Indoor Pollutants, 1981; Szalai, 1972). For example, the National Human Activity Pattern Survey of United States (US) residents found that Americans spend on average $87 \%$ of their time each day in buildings and $6 \%$ in an enclosed vehicle (Klepeis et al., 2001). Worldwide, more people are spending more time in indoor settings, as the rate of urbanization continues to climb from $54.5 \%$ of humans living in cities with at least a half million residents in 2016, to $60 \%$ by 2030 (United Nations [UN] Department of Economic and Social Affairs, 2016). The substantial number of hours people spend in residential, work, health-care, commercial, and transportation facilities amplifies whatever positive or negative effects those settings may have on their health, behavior, and development. For example, levels of indoor air pollution are often several times greater in enclosed settings than in 
outside spaces (Environmental Protection Agency, 2018; Laville, 2018); the longer people are exposed to indoor pollutants, the more negative their effects on behavior and well-being. Further, the microbial profiles of buildings have been found to significantly affect occupants' health (National Academies of Sciences, Engineering, and Medicine, 2017). Also, socially supportive residential and educational settings that are predictable rather than chaotic can have a positive influence on members' developmental outcomes (Evans, 2004; Wachs \& Gruen, 1982).

The pervasive impact of both indoor and outdoor environments on health and behavior is a central concern of human ecology (Borden, 2014; Dyball \& Newell, 2015; Steiner, 2002; Young, 1983). Yet, many research programs in the fields of human and social ecology have given relatively little attention to people's relationships with their indoor surrounds. Notably, the Chicago School of Human Ecology, which emerged in the 1920s, focused mainly on the spatial distribution of population health and behavioral disorders in urban communities (Hawley, 1950; Park et al., 1925), but failed to address the effects of indoor environments on residents' adaptation to their urban milieu. Similarly, more recent conceptions of human and social ecology emphasize macrolevel analyses of societal relations to nature within regional and national contexts, as they affect global sustainability rather than individuals' transactions with indoor environments themselves. For example, see the conceptual and empirical contributions of the Stockholm, Frankfurt, Vienna, and Vermont schools of social ecology (Becker \& Jahn, 2006; Berkes et al., 2003; Bookchin, 2005; Haberl et al., 2016; Hummel et al., 2017).

Conversely, ecological analyses of individuals' and groups' experiences with their everyday proximal environments (rather than society-nature relations viewed at more molar levels) have explicitly examined the influence of indoor settings on occupants. In Roger Barker's (1968) conceptualization of ecological psychology, the principal unit of analysis is the behavior setting-an ecobehavioral system comprised of a physical location, or "milieu," and recurring patterns of individual and organizational behavior that comprise the "behavioral program" of that setting. Behavior settings have both spatial and temporal boundaries, which are located in specific places where recurring activities take place predictably over specified periods. For example, a college course taught in a university lecture hall is a behavior setting that occurs reliably on certain days and at designated times during an academic term. Similarly, the members of a church congregation may attend services every Sunday morning at their place of worship.

A core assumption of ecological psychology is that the physical milieu and behavioral program of a setting are in a dynamic, equilibrium-seeking relationship with each other. Barker (1968) found that understaffed settings, which have fewer members than the number ideally needed to maintain the activities therein, are less selective about whom they admit and from whom they evoke higher levels of commitment. Examples of understaffed settings are events in churches with 
small congregations or sports events at small high schools that have relatively few participants (e.g., a basketball game in which a school's team has five to six rather than ten or more players). In Barker and Gump's (1964) study of high schools in Kansas, smaller schools whose extracurricular settings (such as the editorial office of a school newspaper, or the orchestra, cheerleading and sports teams) were chronically understaffed exerted stronger pressures on students to participate in after-school activities and take on more leadership roles compared to larger schools. These understaffed settings can have long-term effects on the development of students' personalities and leadership skills. In another study of church congregations, the members of small churches on average donated more money at Sunday worship services than those belonging to larger congregations (Wicker, 1969), hence, reflecting higher levels of commitment among the members of understaffed settings.

Unlike understaffed or adequately staffed settings, overstaffed behavior settings have more members and new applicants than are ideally needed to maintain its core functions. The larger the number of applicants seeking membership in a setting (e.g., joining an orchestra, being hired by a new company, or enrolling in a college course), the more stringent the eligibility requirements to join (Wicker et al., 1972). For example, college courses that are highly sought after by students typically manage excess enrollment demand by placing some individuals on a waiting list to ensure the number of class members does not exceed the maximum occupancy of a lecture hall and available instructional resources.

From the vantage point of ecological psychology, behavior settings are the "building blocks" of communities situated within larger geographic regions. Mapping the number and diversity of settings in a city or town affords insights about the social roles available to the members of a population, and the pressures they are under to participate actively in community organizations. Barker and Schoggen (1973) developed methods for surveying the total stock of public behavior settings in a community based on Barker's (1968) "K-21" scales for identifying individual settings in terms of their distinct spatial-temporal boundaries, membership rosters, and core functions (Wicker, 1979). By mapping the distribution of various categories of behavior settings in a region (e.g., recreational settings for adolescent and elderly residents), important features of a community as a whole can be discerned, such as how well it supports the needs and activities of particular subgroups in a population.

Urie Bronfenbrenner's (1979) ecological model of human development also emphasizes the substantial influence of individuals daily activity settings on their social, psychological, and physical well-being. Homes, classrooms, day-care facilities, and workplaces, which often contain multiple behavior settings, are referred to as "microsystems" in Bronfenbrenner's terminology. His model focuses on both the separate and combined influence of multiple, interconnected microsystems on individuals' social and intellectual development, wherein the connections between distinct microsystems (e.g., a child's home and school settings) constitute 
a person's "mesosystems" and "exosystems." In Bronfenbrenner's (1979) model, mesosystems are composed of "two or more settings in which the developing person actively participates (such as for a child, the connections between home, school, and neighborhood peer group; for an adult, among family, work and social life)" (p. 25), whereas exosystems incorporate "one or more settings that do not involve the developing person as an active participant, but in which events occur that affect, or are affected by, what happens in the setting containing the developing person" (p. 25). Examples of exosystems in the case of a young child are his or her parent's place of work and network of friends. Bronfenbrenner (1979) further posited that a person's micro, meso, and exosystems are embedded within the broader community context of the "macrosystem," which encompasses cultural belief systems, and both economic and political circumstances that are pervasive in a society and influence its smaller scale settings. He also introduced the term "chronosystem" to refer to the cumulative developmental influence of a person's micro, meso, exo, and macrosystems over a particular life stage or historical period (Bronfenbrenner, 1994).

Together, Barker's and Bronfenbrenner's ecological models address the influence of people's micro, meso, and macroscale surroundings on behavior and well-being. Their analyses provide both a conceptual bridge between microscale studies of individuals' reactions to local stimuli and environmental conditions-for example, research in environmental psychology on the health effects of exposure to residential crowding, school noise, information overload at work, and indoor or outdoor nature (Cohen et al., 1986; Gifford, 2014; Misra \& Stokols, 2012; Wells \& Evans, 2003) _ and broader-gauged theories of human and social ecology that focus on the interrelations between populations, societies, and the biosphere. Barker's and Bronfenbrenner's ecological models give more explicit attention to the behavioral and health influence of micro and mesoscale ecosystems, relative to macrosocietal theories of human and social ecology. Moreover, many of the settings examined in Barker's and Bronfenbrenner's studies are grounded in indoor environments such as homes, classrooms, and occupational and health-care facilities. Any effort to trace the separate and combined effects of these indoor ecobehavioral systems on members' routine activities and well-being requires that the spatial and temporal coordinates of particular settings be clearly specified.

\section{Dimensions of Change in Contemporary Indoor Environments}

When Barker and Bronfenbrenner were writing in the second half of the twentieth century, the boundaries and structure of people's everyday environments were largely presumed to be stable and distinct. Accordingly, Barker devised on his K-21 assessment criteria to demarcate the unique spatial, temporal, and organizational 
boundaries of nonoverlapping behavior settings. However, in the early twenty-first century, rapid technological, environmental, and sociodemographic shifts began to challenge and blur the previously distinct boundaries surrounding people's indoor ecosystems. These dramatic contemporary changes include the digital revolution and emergence of the cybersphere from the 1980s onward, climate change and the substantial threats it poses to global sustainability, and sociodemographic shifts including population aging, unabated ethnic and international conflict, and the rise of nativism, nationalism, and extreme socioeconomic inequality in many parts of the world.

The ensuing discussion traces some of the recent and anticipated effects of cyber technologies, climate change, and sociodemographic forces on the morphology of indoor ecosystems. Three types of change in environmental morphology are considered: the blurring of spatial, temporal, and organizational boundaries demarcating particular indoor settings; modification of the physical features and social functions of indoor environments; and shifts in the prevalence and distribution of certain categories of indoor settings in host communities, which are likely to continue and accelerate in the coming years. The concluding section examines the broader implications of these structural changes in indoor environments for personal and collective well-being, societal cohesion, and long-term sustainability of the global ecosystem. Looking ahead, broad-gauged transdisciplinary actionresearch strategies will be essential for better understanding and managing complex changes in indoor ecosystems, and their pervasive effects on personal, societal, and global well-being.

\section{Effects of Cyber Technologies on the Form and Functioning of Indoor Ecosystems}

The discovery and rapid deployment of digital information and communications technologies (ICTs) from the late twentieth century onward have substantially changed how people interact with their indoor built environments. The communication links between separate computers through the Internet (pioneered in the 1970s) and the advanced ICTs that followed during the 1980s and 1990s (including Wi-Fi-enabled smartphones and computers, web browsers and search engines, social media, GPS navigation, augmented and virtual reality $[A R, V R]$, artificial intelligence $[A I]$, robotics, the sharing economy, cryptocurrencies, and the Internet of Things) are all part of today's vibrant and multifaceted cybersphere (Stokols, 2018). The digital communications and virtual communities encompassed by the cybersphere (e.g., email and text messaging, online classrooms, bookstores, social media and gaming sites, and scientific collaboratories) are now interwoven with individuals' place-based environments and exert as profound an influence on a person's day-to-day activities, social behavior, and well-being as one's physical (non-virtual) surroundings. 
Individuals' electronic communications with others and their participation in virtual settings always occur within a particular place-based or "real" environment. These real-virtual environment linkages constitute " $\mathrm{R}-\mathrm{V}$ mesosystems" in which a physical place is digitally connected to one or more virtual settings. Whereas Bronfenbrenner's original concept of the mesosystem denoted the links between two or more "real" environments (e.g., a child's home and school), R-V mesosytems are defined by the connections between a particular physical (or real) place, and the virtual transactions and settings that are accessed electronically by occupants located therein (Stokols, 2018). The digital links between real and virtual settings can be complementary —as when a professor shares online resources with students in a classroom to reinforce key points covered in lecture-or they can be conflicted, such as when the behavioral programs of the real and virtual settings contradict each other (e.g., employees checking social media at a workplace are reprimanded by their supervisor for wasting time rather than concentrating on work assignments).

The proliferation of cyber technologies from the 1980s to now has wrought tremendous changes in the form and functioning of people's indoor ecosystems. First, the spatial, temporal, and organizational boundaries associated with residential, educational, occupational, recreational, and commercial settings have become more fluid and less distinct. For example, college courses and work environments are no longer restricted by rigid geographic and temporal boundaries. With the emergence of massive open online courses (MOOCs), thousands of students from around the world can enroll in online seminars, participate in digital discussion groups, and complete course requirements at their own pace without having to attend lectures at specified times in classrooms on a particular campus. Also, the members of work teams and organizations located in different places and time zones can collaborate with each other in real time using online meeting tools such as "GoToMeeting." Individuals can even find friends and romantic partners online through social media (e.g., Facebook, Tinder, and Instagram, among others) without having to meet each other first in a shared physical location such as a restaurant, nightclub, or lounge.

In addition to blurring the spatial, temporal, and organizational boundaries of indoor ecosystems such as educational, work, and recreational settings, the emergence of the cybersphere has increased the polyfunctionality of place-based behavior settings (Stokols et al., 2009). Homes are no longer simply a refuge from work and other non-domestic activities, but now function as electronic hubs for accessing information and entertainment, and performing parental and work-related roles. Employees can telecommute to their corporate offices through computers, and avoid rush-hour traffic to and from work while carrying out their domestic and occupational activities at home. Likewise, many workplaces now incorporate restorative and home-like features, such as child-care facilities, showers, exercise facilities, and meditation rooms for employees. Other cyber technologies such as VR make it possible to enfold a highly immersive virtual environment into one's 
immediate physical setting where such simulations are viewed (cf. Stokols, 2018). Across many different realms of everyday life, indoor environments have become increasingly polyfunctional, as their boundaries have been rendered more permeable and fluid by cyber technologies.

The incorporation of ICTs into our built environments has also altered the form and distribution of indoor ecosystems in communities. Today's residential, educational, commercial, health-care, and work environments must be equipped with Ethernet or Wi-Fi connections to the Internet. Many cafés and restaurants now install computer-friendly work areas enabling customers to go online and complete digital tasks while having a meal or ordering beverages. Automated teller machines (ATMs) and online retailers such as Amazon, Netflix, and eBay have also replaced or necessitated smaller brick-and-mortar banking facilities, movie theaters, and department stores in many cities. Similarly, the proliferation of online news sources such as BuzzFeed, Huffington Post, and many others has led to the constriction and, in some cases, the demise of print newspapers and editorial offices.

\section{Effects of Global Climate Change and Sustainability Threats on Indoor Ecosystems}

Global climate change has been driven by society's excessive reliance on fossil fuels and concurrent spikes in atmospheric greenhouse gas (GHG) emissions triggered by the Industrial Revolution in the eighteenth and nineteenth centuries, and magnified by the Great Acceleration of economic and urban development following World War II (Steffen et al., 2015). The dramatic elevations of carbon dioxide $\left(\mathrm{CO}_{2}\right)$ concentrations in terrestrial and marine ecosystems observed since 1950 are unprecedented in over 800,000 years, based on stratigraphic analyses of $\mathrm{CO}_{2}$ bubbles trapped in polar ice core samples (Intergovernmental Panel on Climate Change, 2015). The steady accumulation of atmospheric GHGs has warmed the planet and unleashed multiple threats to global sustainability. This includes glacial melting, rising sea levels, ocean acidification, biodiversity loss, extreme weather events, as well as regional and international conflicts over increasingly scarce water and food supplies (DiMento \& Doughman, 2014; Sachs, 2015).

The sustainability challenges spawned by the Anthropocene epoch (marked by widespread human-caused planetary change) are imposing stringent constraints on the location, physical features, and social organization of indoor ecosystems. For example, built environments situated in areas most vulnerable to the near-term effects of climate change (e.g., residences located along shorelines, on low-lying islands, in estuaries, and arid regions) will disappear by the end of this century due to sea level rise, flooding, and desertification. Today, nearly half the world's population lives within $150 \mathrm{~km}(93 \mathrm{mi})$ of a coast, and upwards of 200 million people reside near shorelines (Woods Hole Oceanographic Institution, 2018). Most 
will be forced to endure involuntary migration caused by extreme weather events and rising tides. Impoverished groups living in climate-sensitive regions will be affected most severely by these calamitous events, and will have no choice but to flee their homes, joining the growing ranks of climate refugees worldwide (Biermann \& Boas, 2010). These events can be expected to intensify cross-national conflicts about which countries are able and willing to accommodate growing numbers of displaced individuals and asylum seekers (cf. DiMento \& Doughman, 2014).

Indoor ecosystems less immediately threatened by the ravages of climate change will be challenged to become more sustainable and self-sufficient by adopting renewable (e.g., solar) energy technologies and resource conservation strategies (such as participation in community recycling programs). Homes and workplaces will come to rely more heavily on local decentralized technologies such as urban farming, water capture, and solar energy units that can operate "off-grid," independent of large-scale agricultural, water distribution, and electrical power systems (Despommier, 2010; Tomlinson et al., 2015). However, greater independence of indoor ecosystems from centralized civil infrastructures can help fortify community resilience, especially during times of regional resource shortages and intermittencies.

Currently, built environments generate a substantial portion of carbon emissions worldwide, accounting for nearly $40 \%$ of $\mathrm{CO}_{2}$ produced in the US alone (Gardner \& Stern, 2008). As such, the owners and occupants of indoor settings will face increasing pressures to reduce their carbon footprints through ecological design strategies (Van der Ryn \& Cowan, 2007), while urban dwellings will become more compact and densely concentrated to improve energy efficiency. One example of an ecological accounting system that encourages "green design" (e.g., through the use of local, nontoxic construction materials, recycling and waste reduction, improved indoor environmental quality, and management) is the US Green Building Council's (2018) Leadership in Energy and Environmental Design (LEED) Program. Such evaluations of buildings have proven to be effective in curtailing adverse environmental effects of public and corporate facilities. LEED-certified buildings have $34 \%$ lower $\mathrm{CO}_{2}$ emissions, and consume 25\% less energy and $11 \%$ less water than comparable non-LEED facilities (US Green Building Council, 2017). Improvements in the design of indoor ecosystems will continue to be at the forefront of future efforts to enhance global sustainability.

\section{Influence of Sociodemographic Forces on the Form and Prevalence of Indoor Ecosystems}

In conjunction with global trends toward digitalization and planetary warming, sociodemographic forces also are reshaping the form and distribution of many built environments. Population aging in several countries is prompting greater investment in and prevalence of assisted living environments for the elderly, as well as inpatient and outpatient health-care settings. Further, to enable older persons to remain in 
their own dwellings for as long as possible before transitioning to assisted living arrangements, there will be a growing need to retrofit existing stocks of residential settings with universal design features as people age. Future environmental design and planning strategies to support older adults" desire to live independently and "age in place" in the comfort of their own dwellings can benefit by adopting an ecosystem approach that combines indoor universal design features with outdoor affordances, such as proximity to neighborhood transit lines and retail services. Achieving these ecologically grounded solutions to better accommodate the housing needs of an aging population calls for transdisciplinary action research strategies to sustain close collaboration among environmental designers, urban planners, gerontologists, elected officials, and community stakeholders (cf. Brown et al., 2010).

Another sociodemographic trend that is reshaping the form and prevalence of indoor ecosystems is the rising tide of intolerance toward minority groups and "outsiders" now evident in many countries. The recent surge of nationalism and anti-immigrant sentiments around the globe (e.g., the "America First" and "Brexit" movements in the US and the United Kingdom, respectively) has fueled a burgeoning refugee crisis worldwide, starkly evident now in the Middle East, portions of Africa, and the Mexico-US border. The victims of racism and xenophobic nationalism have been forced into nomadic, migratory lifestyles in lieu of secure and stable living conditions, while refugee camps offering transitory shelter and minimal amenities have sprung up in conflict zones. Interethnic hostilities and cross-national immigration policies, together with the immediate climate change dangers that especially threaten impoverished, minority, and homeless people, have only exacerbated the current refugee crisis (Chakalian, 2018; DiMento \& Doughman, 2014). Further aggravating these societal and public health dilemmas are the extreme levels of socioeconomic inequality that exist throughout the world (Piketty, 2014; Sassen, 2014). To counter these interlinked crises of poverty, persecution, inequality, homelessness, and refugee status, new forms of modular semipermanent housing (i.e., portable, compact, hygienic, secure, and affordable dwellings) must be constructed and made available to vulnerable families and ethnic groups in the coming years.

In the case of more affluent cyber-enabled environments, changes in indoor settings sparked by the rise of the Internet and other cyber technologies have modified individuals' behavior and societal functioning in myriad ways. Digitized homes permit residents to order groceries, perform work, manage finances, take courses, consult news media, watch movies, and interact with friends online without ever having to leave the confines of their homes. These trends toward residential "cocooning" may increase separation and polarization among the members of diverse groups that reside in a community. The more time individuals spend alone or with like others in their homes and the fewer opportunities they have to interact with dissimilar others, the greater the potential for societal fragmentation, "narrowcasting" of information and communication sources, and loss of the public sphere in favor of solipsistic individualism pursued within privatized settings. 


\section{Looking Ahead}

The emergence of the cybersphere, sustainability challenges of the Anthropocene, and contemporary sociodemographic trends have together radically reshaped the form, functioning, and distribution of indoor ecosystems in communities. As people spend so much of their time in built environments, the restructuring of indoor settings in effect has altered the very fabric of society and daily life. Some of the modifications in such spaces attributable to digitalization, climate change, and sociocultural shifts have been for the better. The Internet has made the spatial and temporal boundaries of indoor ecosystems less restrictive, affording tremendous conveniences for the occupants of residential, educational, occupational, commercial, and recreational settings-for example, by enabling them to collaborate with coworkers, interact with friends, and meet romantic partners located in distant places.

Simultaneously, the greater permeability of indoor ecosystems resulting from their online connections to remote locations has increased the polyfunctional and multitasking qualities of those settings. Notably, the transformation of residential environments from a domestic refuge away from work into a multi-activity hub could have potentially negative ramifications by enabling millions of household members to conduct most of their day-to-day activities inside their dwelling, without having to venture outside and encounter a diversity of other people in public venues, such as movie theaters, concert halls, and shopping centers. These changing patterns of residential life, to the extent that they become more pervasive in future years, could erode the foundations of public life and societal cohesion altogether.

Similarly, the effects of climate change on indoor ecosystems reflect a mix of potentially negative and positive outcomes. That is, built environments located in areas most immediately exposed to the dangers of climate change are doomed to extinction, as they are overtaken by inexorable sea level rise, flooding, and desertification. Conversely, the sustainability challenges posed by the Anthropocene have spurred technological innovations that, ultimately, will reduce the carbon footprints of buildings, increase their use of renewable energy sources, and enable them to become more self-sufficient and resilient.

We are now at a pivotal time in history when humans can seize the initiative to restructure indoor ecosystems in ways that support civil society, inclusive governance, and environmental sustainability. As a basis for creating indoor settings that are more healthful, efficient and robust, broad-gauged transdisciplinary action research spanning multiple scales (from local to global) and diverse fields will be necessary (Stokols, 2006). International treaties such as the Montreal Protocol, to ban ozonedepleting substances, and the Paris Agreement, to reverse climate change, have proven to be effective macrolevel strategies for advancing global sustainability goals (UN Environment Programme, 2018; UN Framework Convention on Climate 
Change, 2018); however, they should be combined in future years with micro and mesoscale changes in the design and organization of indoor ecosystems as part of multi-level initiatives to protect the biosphere (Stokols, 2018). Achievement of these ambitious action-research goals will call for new educational approaches that prepare future generations of human and social ecologists to analyze environmental and societal problems from a transdisciplinary, multilevel systems perspective.

\section{References}

Barker, R. G. (1968). Ecological psychology: Concepts and methods for studying the environment of human behavior. Stanford, CA: Stanford University Press.

Barker, R. G., \& Gump, P. V. (1964). Big school, small school. Stanford, CA: Stanford University Press.

Barker, R. G., \& Schoggen, P. (1973). Qualities of community life. San Francisco: Jossey-Bass Publishers.

Becker, E., \& Jahn, T. (2006). Social ecology: Outlines of a science of social relationships with nature. Frankfurt, Germany: Campus.

Berkes, F., Colding, J., \& Folke, C. (Eds.). (2003). Navigating social-ecological systems: Building resilience for complexity and change. Cambridge, UK: Cambridge University Press.

Biermann, F., \& Boas, I. (2010). Preparing for a warmer world: Towards a global governance system to protect climate refugees. Global Environmental Politics, 10(1), 60-88. doi.org/ 10.1162/glep.2010.10.1.60

Bookchin, M. (2005). The ecology of freedom: The emergence and dissolution of hierarchy. Oakland, CA: AK Press.

Borden, R. J. (2014). Ecology and experience: Reflections from a human ecological perspective. Berkeley, CA: North Atlantic Books.

Bronfenbrenner, U. (1979). The ecology of human development: Experiments by nature and design. Cambridge, MA: Harvard University Press.

Bronfenbrenner, U. (1994). Ecological models of human development. In T. Huston \& T. N. Postlethewaite (Eds.), International encyclopedia of education (2nd ed., vol. 3, pp. 1643-1647). New York, NY: Elsevier.

Brown, V. A., Harris, J. A., \& Russell, J. Y. (Eds.). (2010). Tackling wicked problems through the transdisciplinary imagination. London, UK: Earthscan.

Chakalian, P. (2018, June 25). Homeless people are dying at an alarming rate because of climate change. Mother Jones. Retrieved from www.motherjones.com/environment/2018/06/ homeless-people-are-dying-at-an-alarming-rate-because-of-climate-change/ 
Cohen, S., Evans, G. W., Stokols, D., \& Krantz, D. S. (1986). Behavior, health, and environmental stress. New York, NY: Plenum Press.

Despommier, D. (2010). The vertical farm: Feeding the world in the 21st century. New York, NY: Thomas Dunne Books, St. Martin's Press.

DiMento, J. F. C., \& Doughman, P. (Eds.). (2014). Climate change: What it means for us, our Children, and our grandchildren. Cambridge, MA: MIT Press.

Dyball, R., \& Newell, B. (2015). Understanding human ecology: A systems approach to sustainability. London, UK: Routledge.

Environmental Protection Agency. (2018). Report on the environment: Indoor air quality. Retrieved from www.epa.gov/report-environment/indoor-air-quality

Evans, G. W. (2004). The environment of childhood poverty. American Psychologist, 59(2), 77-92. doi.org/10.1037/0003-066X.59.2.77

Gardner, G. T., \& Stern, P. C. (2008). The short list: The most effective actions U.S. households can take to curb climate change. Environment: Science and Policy for Sustainable Development, 50(5), 12-25. doi.org/10.3200/ENVT.50.5.12-25

Gifford, R. (2014). Environmental psychology: Principles and practice (5th ed.). Colville, WA: Optimal Environments.

Haberl, H., Fischer-Kowalski, M., Krausmann, F., \& Winiwarter, V. (Eds.). (2016). Social ecology: Society-nature relations in time and space. Dordrecht, Netherlands, Heidelberg, Germany, New York, NY, London, UK: Springer.

Hawley, A. H. (1950). Human ecology: A theory of community structure. New York, NY: Ronald Press Company.

Hummel, D., Jahn, T., Keil, F., Liehr, S., \& Stieb, I. (2017). Social ecology as critical, transdisciplinary science-conceptualizing, analyzing and shaping societal relations to nature. Sustainability, 9(7), 1050. doi.org/10.3390/su9071050

Intergovernmental Panel on Climate Change. (2015). Climate change 2014: Synthesis report. In Core Writing Team, R. K. Pachauri \& L. A. Meyer (Eds.), Contribution of working groups I, II and III to the Fifth Assessment Report of the Intergovernmental Panel on Climate Change. Geneva, Switzerland: IPCC. Retrieved from ar5-syr.ipcc.ch/

Klepeis, N. E., Nelson, W. C., Ott, W. R., Robinson, J. P., Tsang, A. M., Switzer, P., ... Engelmann, W. H. (2001). The National Human Activity Pattern Survey (NHAPS): A resource for assessing exposure to environmental pollutants. Journal of Exposure Analysis and Environmental Epidemiology, 11(3), 231-252. doi.org/10.1038/sj.jea.7500165

Laville, S. (2018, May 24). Air pollution worse inside London classrooms than outside, study finds. The Guardian. Retrieved from www.theguardian.com/environment/2018/ may/24/air-pollution-worse-inside-london-classrooms-than-outside-study-finds

Lewin, K. (1951). Field theory in social science. New York, NY: Harper \& Row. 
Misra, S., \& Stokols, D. (2012). Psychological and health outcomes of perceived information overload. Environment and Behavior, 44(6), 737-759. doi.org/10.1177/ 0013916511404408

National Academies of Sciences, Engineering, and Medicine. (2017). Microbiomes of the built environment: A research agenda for indoor microbiology, human health, and buildings. Washington, DC: National Academies Press. doi.org/10.17226/23647

National Research Council (US) Committee on Indoor Pollutants. (1981). V: Factors that influence exposure to indoor air pollutants. In Indoor pollutants. Washington, DC: National Academies Press. Retrieved from www.ncbi.nlm.nih.gov/books/NBK234048/

Park, R. E., Burgess, E. W., \& McKenzie, R. D. (1925). The city. Chicago, IL: University of Chicago Press.

Piketty, T. (2014). Capital in the twenty-first century (A. Goldhammer, Trans.). Cambridge, MA: Belknap Press of Harvard University Press.

Rosenfield, P. L. (1992). The potential of transdisciplinary research for sustaining and extending linkages between the health and social sciences. Social Science and Medicine, 35(11), 1343-1357. doi.org/10.1016/0277-9536(92)90038-R

Sachs, J. D. (2015). The age of sustainable development. New York, NY: Columbia University Press.

Sassen, S. (2014). Expulsions: Brutality and complexity in the global economy. Cambridge, MA: Harvard University Press.

Steffen, W., Broadgate, W., Deutsch, L., Gaffney, O., \& Ludwig, C. (2015). The trajectory of the Anthropocene: The great acceleration. The Anthropocene Review, 2(1), 81-98. doi.org/10.1177/2053019614564785

Steiner, F. (2002). Human ecology: Following nature's lead. Washington, DC: Island Press.

Stokols, D. (2006). Toward a science of transdisciplinary action research. American Journal of Community Psychology, 38(1-2), 63-77. doi.org/10.1007/s10464-006-9060-5

Stokols, D. (2018). Social ecology in the digital age: Solving complex problems in a globalized world. London, UK: Elsevier Academic Press.

Stokols, D., Misra, S., Runnerstrom, M. G., \& Hipp, J. A. (2009). Psychology in an age of ecological crisis: From personal angst to collective action. American Psychologist, 64(3), 181-193. doi.org/10.1037/a0014717

Szalai, A. (Ed.). (1972). The use of time: Daily activities of urban and suburban populations in twelve countries. The Hague, Netherlands: Mouton \& Co.

Tomlinson, B., Nardi, B., Patterson, D. J., Raturi, A., Richardson, D., Saphores, J.-D., \& Stokols, D. (2015, December). Toward alternative decentralized infrastructures. Paper presented at the Proceedings of the 6th Annual Symposium on Computing for Development, London, UK. doi.org/10.1145/2830629.2830648 
United Nations Department of Economic and Social Affairs. (2016). The world's cities in 2016 [Data file]. In World urbanization prospects: The 2014 revision. New York, NY: United Nations. Retrieved from www.un.org/en/development/desa/population/ publications/pdf/urbanization/the_worlds_cities_in_2016_data_booklet.pdf

United Nations Environment Programme. (2018). About Montreal Protocol. Retrieved from web.unep.org/ozonaction/who-we-are/about-montreal-protocol

United Nations Framework Convention on Climate Change. (2018). The Paris Agreement. Retrieved from unfccc.int/paris_agreement/items/9485.php

US Green Building Council. (2017). Benefits of green building. Retrieved from www.usgbc. org/articles/green-building-facts

US Green Building Council. (2018). Better buildings are our legacy: LEED is green building. Retrieved from www.usgbc.org/leed

Van der Ryn, S., \& Cowan, S. (2007). Ecological design (2nd ed.). Washington, DC: Island Press.

Wachs, T. D., \& Gruen, G. E. (1982). Early experience and human development. New York, NY: Plenum Press.

Wells, N. M., \& Evans, G. W. (2003). Nearby nature: A buffer oflife stress among rural children. Environment and Behavior, 35(3), 311-330. doi.org/10.1177/0013916503035003001

Wicker, A. W. (1969). Size of church membership and members' support of church behavior settings. Journal of Personality and Social Psychology, 13(3), 278-288. doi.org/10.1037/ h0028272

Wicker, A. W. (1979). An introduction to ecological psychology. New York, NY: Cambridge University Press.

Wicker, A. W., McGrath, J. E., \& Armstrong, G. E. (1972). Organization size and behavior setting capacity as determinants of member participation. Behavioral Science, 17(6), 499-513. doi.org/10.1002/bs.3830170602

Woods Hole Oceanographic Institution. (2018). Understanding the ocean. For our planet and our future. Retrieved from www.whoi.edu

Young, G. L. (Ed.). (1983). Origins of human ecology. Stroudsburg, PA: Hutchinson Ross. 
This text is taken from Human Ecology Review, Volume 24, Number 2, 2018, published by ANU Press, The Australian National University, Canberra, Australia.

doi.org/10.22459/HER.24.02.2018.02 